\title{
HOW IS SOCIAL WORK AFFECTED BY DIFFERENT CONTEXTS?
}

GLORIA LUCY CHISALA

MALAWI 


\section{INTRODUCTION}

Social Work is one of the oldest professions, dating back to pre-industrial societies - even though it may not then have been called social work. It is a profession that deals both with society and individuals. Social work has been changing as the society has evolved, which in turn entails changes in peoples behaviours. Society and the individual are caught in an intense and changing relationship whereby each one seeks to influence the other. Moreover social work seeks to influence society (and individuals within it) and society in turn seeks to set limit on what social workers should do and should not do. So, social work is situated in the middle pulled between the individual and society, the powerful and the excluded, negotiating, and at times in conflict with both.

On the other hand, it must be borne in mind that these societies are not homogenous, in terms of, their social, political, and economic structures. Cree as cited by Davies (2002) argues that social work deals with societies that are full of diversity. Consequently, social work theories and approaches must be adapted to suit the context, in which they are applied at any particular time, hence social work practice differs according to the context in which it is found. To properly understand these contexts, there is need for an holistic approach to social work. This paper therefore aims to discuss and explain how different contexts affect social work. It will also attempt to draw lessons from different contexts on how to be effective. For the purposes of this paper emphasis will be put on specific issues that have been derived from the broader contexts. Examples from my own practice and other experiences will also be used.

\section{DISCUSSION}

Social work is a profession that operates in different contexts with a range of players in complex situations, whose interests, perceptions, culture, social functions are different. Thus, social work in developed countries such as Norway, United Kingdom, Denmark, United States of America and Sweden is different from social work in developing countries like Malawi, Uganda, Ethiopia and Tanzania. These characteristics of social work arise due to a number of differences in terms of resources, national policies, social problems, culture, and religion amongst other aspects. In addition, social work has many elements comprising of ethics, values and practices, theories, knowledge and practitioners. Many of these complexities contradict each other and interests clash (Ife 1997 cited by Fook 2002:3). He further argues that social work is a function of and response to the many different contexts in which it operates. I would generalise by saying that material, social, political, economic, global and cultural contexts are some of the broader contexts that are affecting social work.

Personal contexts of the social worker affect their practice. Social workers are both professionals and employees. They are also citizens, community members in the global and local contexts. They have their own background, values, beliefs, interests and education. All these elements when combined affect their interaction with clients and influence the assumptions and judgements that a social worker makes in respect of a particular client (Shulman 1991). These judgements may compromise the values and ethics of the profession even though the outcome of the judgement may be good. There are examples of workers who have taken advantage of the profession to advance their own personal interests. For example, in my experience one of the social workers married a client who was visiting the social welfare office together with her husband for marital counselling. The social worker, instead of helping this couple, ended up proposing the woman and married her. Of course the husband did not sue him. Such behaviour is common among social workers in some parts of the world. But what picture did this social worker paint for the profession? The integrity and credibility of the profession could therefore be questioned. In Malawi, we do not have registered social workers and national codes of ethics for guidance - a possible reason for such types of behaviour. In 
countries where the social work profession is secure and there are codes of ethics in place, then this kind of behaviour among social workers is less likely. For example, in South Africa, social workers are registered and have a national association and codes of ethics: if a social worker is caught behaving in this manner he or she would be penalised and the license would be taken away from them.

Other factors within the personal context of the social worker, such as stress and motivation affect the way he or she interacts with clients. Usually, social workers have a lot of work to do. In Malawi, there are shortage of social work staff and you may find one social worker managing a lot of activities in the office. So if a client visits him or her little attention is paid to that client, sometimes social workers do not even bother to go in details of clients' needs. Motivation affects social work. Usually the salaries are too low to motivate staff. The working conditions are also very poor, for example resources like papers, computers, and transport are very difficult to get. Because of this, other social workers do not go to the office, and if they go, they will go and attend meetings that they know they will get money for home. Van Wormer (1999), talks of social workers in United America she observes that social workers, because they are found in stressful positions, they tend to gravitate toward private practice. In Malawi they also experience high levels of stress and at the same time there are no resources. Moreover, the level of education among social workers does affect the quality of social work. If they are not properly trained, the quality of services is also poor. In Malawi, there are cases when a social worker is not even able to conduct an assessment of the client due to their poor educational background. All these issues are detrimental to the profession.

Social work is a profession based on dealing with social problems. However, these problems are differently defined according to the context. What is considered as a problem in one context may not be regarded as such in another. Examples of such social problems could be poverty; diseases like HIV/AIDS, malaria and mental disorder; war and migration just to mention a few. Variation of resources and institutional may affect social work interventions in terms of support available in solving those problems. For example, poverty affects about four percent of Danish citizens, whereas in Africa, Asia, and in many countries of the exSoviet Union, poverty is a mass phenomenon (Healy 2001). This difference severity shapes the social work response - intervention by social workers in Denmark would differ from that of Africa or Asia. Most of countries in Africa, like Malawi, are not welfare states, hence social workers have to find other means other than organised state welfare to solve problems. To take an example from Malawi, on how communities have organised themselves in dealing the impact of HIV/AIDS, such as caring of orphaned children. However, despite having the same problem, the approaches used are different from those employed in Western countries, (e.g. United States of America), where the state and parent would plan for the future of the child if the parent was suffering from AIDS. In Malawi parents and state do not plan for the future of children before the carer dies and the child is orphaned. Thus community-based organisations established by family groups, faith based organisations and other well-wishers are running programmes to look after the children. The state assists by providing training for the staff in these organisations about how they can effectively care for children. Therefore, mass poverty requires social and community development approaches where as individualised poverty in welfare states of Denmark, for example, can be addressed through referrals for entitlements. So even though problems are the same they will require local interventions depending on resources and institutional support available. Regarding Payne (2005) societies construct the kind of social work that responds to their views of social issues and the way it would be possible to deal with them.

The history of colonialism and domestic policies in most African countries has influenced the kind of approaches to social work being undertaken. In most parts of Africa; social work was introduced by the British colonialists, (e.g. Uganda, Malawi), in the early 1930s. However, the approaches used then were more useful in resolving the type of individual problems found 
in western societies. This residual and individualised approach, dominated social work for the first thirty years. Yes, this approach could not effectively work in most African countries, where the majority are poor and resources are lacking. The type of social work during this period was only for those people who were working for the missionaries mainly education and medical care. This form of social work was highly selective and did not benefit everyone. In the post-colonial era most countries in the Southern African Development Cooperation (Malawi, Botswana, Zambia, Swaziland, Lesotho, Zimbabwe) opted to achieve development by concentrating on economic growth, on the assumptiom that wealth would trickle down to the grass roots. Hence, the development policies adopted were only those that benefited a few of the urban elite. For example in Malawi, the emphasis was placed on commercial farming - half of the government's total financial allocation was put in this sector of the economy. This ignored the needs of the rural people who constitute ninety percent of the population. Little emphasis was placed on the social services sector. Again these social services sectors i.e. (schools, hospital and water), were not easily accessible to poor people (Bwalo 1999). This has had implications in terms of literacy rates, health and nutrition status of the population in Malawi. This notion of trickle down development is still now used by the World Bank and International Monetary Fund in the Structural Adjustment Programmes and Poverty Reduction Strategies (PRSPs). Hence these kinds of policies used in most African countries excluded a lot of people, especially the poor, from benefiting from social services like education and health.

Social work is affected by the organisational context. Social workers are employees in public and private organisations, which have policies, guidelines, visions and missions, priorities, objectives and mandates to which a social worker is supposed to comform to. Fook (2002) argues that these various documents place control of professional practice in hands of managers and bureaucrats. Instead of making decisions that will solve clients' problems, social workers are made to adhere to the rules, values and guidelines of their agencies. Similarly, as much as social workers are supposed to advocate for client self-determination in problem solving (through empowering clients to make decisions), they may not allow clients to act in the manner they wish because they are accountable to the employer and legislative framework that authorises social work intervention. The means that attaining organisational objectives may take priority over the objectives themselves. Hence, sometimes objectives may become lost or forgotten; efficiency and predictability take precedence over any other consideration (Adams 1986 cited by Fook 2002). A good example from my own experience in working with UNICEF Malawi. This organisation has its own priority areas of operation and they tend to fund only those activities which are in line with their goals and mission.

\section{Example From Practice I}

"There are many times when you present a list of activities to this funding agency, but only to be told that the activities are not in line with their priorities. And when we are approaching the end of the financial year, they pressurise us to create activities so that the money does not return back to their funding agencies as well. So it is like we are implementing activities that are aiming at advancing interests of our funding agencies. For them, efficiency is their number one priority, which conflicts against the values and ethics of a social work of which social workers are supposed to abide to. So it is like you are in dilemma as to which is which?"

The process of globalisation are another current major challenge affecting social work. The capitalist imperialism of capitalism which is characterised by competition, efficiency and effectiveness and profit maximisation poses problems on delivery of social work. Social work is a profession that relies much on state for public funding. This is true for Western world. According to Fabricant and Burghardt (1992 cited by Fook 2002), ague that it is unfortunate that the scope and range of the 'welfare state' is being reduced in the modern capitalist society. 
Where all too often the profession of social work, a part of the welfare state is seen to be a nonprofit making that contributes nothing to the economy; hence, cutbacks in public or social spending and promotion of privatisation of these public infrastructures become justifiable. Kennet (2001) comments that the influence of supranational actors has been increased through globalisation processes. She argues that social policy of a country or locality is no longer wholly shaped by politics of national government. Global institutions such as the World Bank, International Monetary Fund, Organisations for Economic Cooperation and Development (OECD) and the European Commission are shaping national government's policies. In Malawi, as well as in all other developing countries, structural adjustment programmes have done more harm than good. Since developing countries began to implement such programmes, a lot of people have become poorer than they were ten years previously. Privatisation of state owned companies has left some ninety percent of the population unemployed. The cutbacks in education and health sectors compromise the quality of services that a poor person would access; for example, in schools, teachers receive low salaries, and there are inadequate learning materials while in hospitals there are no drugs and other health facilities. Removal of subsidies in agricultural items means that the poor cannot afford to purchase farming requirements. Diseases such as cholera, diarrhoea and malaria (which are commonly called as diseases of the poor) are very common especially among the poor women and children. With such inequalities a consequence of globalisation, how will social work achieve social justice, empowerment and self-determination?

The task of social work, and to some extent, its forms of practice are influenced by the social welfare systems in which it is located. Comparing welfare models of Scandinavian countries (Sweden, Norway and Denmark) and United Kingdom, social work is differently constructed . For example, in the Scandinavian model, the emphasis on universalism has given every citizen an entitlement to social insurance, where as in the UK Welfare model it is not universalistic but selective and focuses predominantly on those with limited income in other words the poor. Lorenz (1994) comments that in Sweden social workers are directly involved in evaluating and developing services in line with changing needs, as compared to UK. The British System leaves a lot of people, who are poor without intervention, yet who will continue rely upon social welfare for assistance. Comparing these same with Malawi; for example, Malawi is not a welfare state. Social work is provided by various players that include government departments, non-government organisations, faith based organisations and community based organisations. The government does not have special funding or resources to provide social insurance for poor people. You cannot go to the government to seek for social and economical support if you are poor.

Technological advancement is affecting social work in one way or the other. Fook (2002) argues that changes in technologies have revolutionised the context in which professionals operate. The use of advanced technology such as telephones and the internet are posing a challenge to the profession. In order to meet the demands for efficiency and utility social workers in developed countries can conduct interviews or counselling with their clients through a telephone or via internet without physically seeing them and may be increasingly likely to do so. The nature of professional expertise and the relationships between professional and clients are changed as a result of these new developments. Similarly lack of access to such technologies are a further mechanism for perpetuating social exclusion of clients who do not own these resources. This is true for industrialised nations. The challenge is how to make new technologies inclusive rather exclusive.

Social work is a profession whereby practitioners work with various groups of people who themselves always affect practitioners ways of thinking and judgements As social workers interact with communities and clients who belong to different personal contexts to those of the social worker, in respect of background, language, culture, values, ethnicity, identity, race and gender. For example, social workers may experience a range of challenges when they 
are working with immigrants or refugees, which affect the social worker's interactions and judgements. For example, language would limit explanation of a problem or the creation of an 'arena for understanding' between a social worker and client. Concepts that describe particular phenomena may not be familiar to either a social worker or a client. Both would lack contexts within which refer to elements that the language describes and explains. Professionals are challenged in how to assist migrants adapt to their new settlement so that they do not feel socially excluded and discriminated; for example, how are they going to adapt to modern secular societies if they come from societies where traditional skills have been passed on from those who have technical skills; or from extended families in homogenous societies to isolation and segregation in heterogeneous and from societies stressing family obligations to those stressing independence.

Howe (1987) argues that different societies construct or create their own social world which is only fully understood from the point of view of the people directly involved in whatever activity is being considered - their context. Thus in order to understand other people, we must learn of his or her reason, and to change things for people, we must plan with them and not for him. This has deep implications for the way a social worker approaches, understands and works with his or her client. If social workers are not aware of these different contexts, they may end up seeing clients' histories only from their own point of view. They will never understand the real story. Hence the challenge for social workers, working with different groups of people.

Cultural contexts may thus affect the implementation of some policy issues that social workers seek to advocate. As already stated, social work operates in societies which have different cultures. Culture is made up of beliefs, customs, values, ideas, language, ethnicity. . Giddens (2001) states that these elements are constructed, learned and shared by members of society, and that culture allows cooperation and communication to take place. For example, some societies are individualistic while others are collectivistic. Social work operates in these different cultural contexts where elements of society's culture may conflict with ethics and values of the profession, or human even rights issues. A social worker might find herself or himself trapped in a situation which requires both the adherence to professional values and at the same time ensuring respect for the cultures of its clients and carers. Adapting professional principles to these different cultural contexts may not therefore be an easy to achieve. Practitioners often encounter situations that can cause moral discomfort and raise ethical dilemmas as they interact with different cultures. They struggle with debates universalist- or relativist over the extent to which practice should be.

Taking an example of how different cultures in individualistic and collectivistic societies respond to issues of human rights, it may be found that some societies will easily accept principles of self-determination, equality, non discrimination and confidentiality just to mention a few, while to others such ideas are taboo. For example, in many African or Asian countries which are collectivist societies it may be difficult to implement child rights and ensure human rights. Gender issue is a good example; from my own practice in Malawi, where the promotion of gender equality among men, women, boys and girls is a large problem for social workers as there is resistance to the establishment of an equal society not only from the communities but also from the top levels in government and private sector bodies. This is because in my culture women are expected to always to be loyal to the male counterparts and social norms do not allow women to pursue activities that will empower them economically in society. In other words, women should not expect to be equal with men in anything! If a single woman for example is successful in life, people will suspect that she is a prostitute that this is why she has managed to accumulate the riches despite her capabilities. There are duties and roles that have been socially constructed by Malawian society that define what should be performed by and is expected of men, women, boys and girls. However, taking the same issue of gender equality, in Norway, where the society is individualistic, resistance from people is less than in collectivistic societies. In Norway, people are socialised to be independent and 
equal opportunity is given to everyone. The disparities between men and women are low in mine spheres of life.

\section{Example From Practice II}

"Early this year I was assigned to attend a policy review meeting of the Malawi Poverty Reduction Strategy, which is the main policy document that guides implementation of poverty alleviation programs. This document has been criticised by both national and donor community for being gender insensitive, as it has been silent on statistics as to who and how many people (in terms of gender) have benefited from the programmes and also on how it was going to benefit the majority of the poor people, who are mainly women and children. So this year, they invited me and other people dealing with gender issues to assist with the mainstreaming of gender in the document. It was really a struggle to convince even the team that comprised of University Lecturers and top government officials. When you wanted to speak, they could stop you without even listening to what you are saying. I got furious and the following day I did not attend because they could not accept our views. One of them asked me why I decided to join with 'gender' issues because it was a profession for those people who are frustrated in life and do not have stable families. I did not answer him. This is just one of the stories and I have encountered in several other situations. So it is really a challenge for social worker in Malawi."

These people, being well educated, you would expect them to understand and grasp such issues easily. But I learnt that they would be resistant because of the way they have been socialised. They have beliefs and practices which they can not just change, I also thought that these people could be argumentative and resist my views because of my employment position, they occupied a much higher position in the organisational hierarchy. Or it could because of the very presence of women in that meeting.

Similarly, the implementation of children's rights is affected by culture, principles of participation and self-determination, are differently implemented depending on cultural context. In Norway and other Western European Countries there appears to be an increasing trend for young people to make decisions regarding their personal affairs, independent of views of their parents. In many parts of Africa, this is not the case. Culturally, children are not supposed to decide anything about their personal affairs otherwise the parent will think that they are rude. As long as they are staying with the parent they are not supposed to make decisions without consulting a parent.

\section{CONCLUSION}

In this paper, it has been shown that these different contexts in which social work is operates have implications for the delivery of social work itself, for social workers (in terms values and ethics) as well as social and welfare policy. My question now could be how do social work and social workers operate effectively in these different contexts? These are the lessons that I have learnt and which suggested a way forward based upon experiences as discussed throughout this essay:

- Social workers need a thorough understanding of different contexts. This can be achieved through broadening of their skills so that they are able to transmit knowledge in different situations, this could also be achieved through the use of reflective and reflexive approaches. Throughout my experiences, shown in the examples, I also learnt that resistance may occur when dealing with people with different cultural, political, biological, historical backgrounds. Hence, social workers should be creative in their approaches. 
- I have learnt that social workers, who are operating in different contexts, should always be in a position to explore with communities and clients the extent to which the cultural practices or beliefs in question are core to the maintenance of culture or harmful to other groups of people. Thus social workers must be able to deconstruct policies, peoples perceptions, cultures and beliefs that result in social injustice.

- Social workers must have knowledge of international social work as this would help them to gain a full and proper understanding of different cultural, political and historical contexts of particular societies. This will also help them to understand why certain people are behaving in a particular way and facilitate planning, and plan how to work with such clients and carers.

Considering these contexts, social workers must always be aware of both in international as well as local contexts. They must not only have knowledge about the contexts but also must be creative about how they can effectively apply the theories learnt in a formal class environment into practice, which is composed of these different contexts. Social workers need to change their ways in which they conceptualise their skills. They must broaden their skills for effective translation and communication about what values and goals of social justice mean to different people and groups. However, there are other issues that are beyond the control of a social worker for example the globalisation processes, which are currently threatening the profession in terms of social welfare policy, this opens up further questions for the future.

\section{BIBLIOGRAPHY}

Adams R., Dominelli L., Payne M., (eds) (2002) Social Work: Themes, Issues and Critical Debates. New York. Palgrave.

Bwalo (1999).Sustainable Social and Human Development, University of Malawi

Cohen R. \& Kennedy P. (2000) Global Sociology, Great Britain

Davies M. (eds) (2002) The Blackwell Companion to Social Work, London Blackwell.

Dominelli L. (2002) Anti- Oppressive Social Work theory and Practice, Houndmills, Basingstoke,: Palgrave Macmillan

Fook J. (2002) Social Work: Critical Theory and Practice, London Sage Publication Ltd.

Giddens A. (2001) Sociology, London: Blackwell

Healy L.M. (2001) International Social Work: Profession Action in an Interdependent World, New York: Oxford University.

Howe D. (1987) An Introduction to Social Work Theory: Community Care Practice Handbook, Cambridge: Wildwood House.

Kennet P. (2001) Comparative Social Policy: Theory and Practice, Milton Keynes: Open University Press.

Lorenz W. (1994) Social Work in a changing Europe, London: Routledge. 
Malawi Government (2002), Malawi Poverty Reduction Strategy, 2002

News Batch, Globalisation and Social Policy, Cromwell Press Limited

Payne, M, (2005) Modern Social Work Theory, Third Edition Palgrave MacMillan

Shardlow S. Payne M. (Eds) (1998) Contemporary Issues in Social Work: Western Europe, Aldershot: Arena Ashgate

Shulman L. (1991) International Social Work Practice: Towards an Empirical Theory, USA. F.E Peacock Publishers Inc.

Van Wormer, K (1999) Social Welfare: A World View Belmont; CA : Wadesworth 